CILENE MARIA MARQUES GONÇALVES

MÉTODO PARA GESTÃO DO CUSTO DA CONSTRUÇÃO NO PROCESSO DE PROJETO DE EDIFICAÇÕES 


\section{MÉTODO PARA GESTÃO DO CUSTO DA CONSTRUÇÃO NO PROCESSO DE PROJETO DE EDIFICAÇÕES}

Dissertação apresentada à Escola Politécnica da Universidade de São Paulo para obtenção do título de Mestre em Engenharia

Área de Concentração: Engenharia Civil e Urbana

Orientador: Professor Livre-Docente Silvio Burrattino Melhado 
Este exemplar foi revisado e alterado em relação à versão original, sob responsabilidade única do autor e com a anuência de seu orientador.

São Paulo, de março de 2011.

Assinatura do autor

Assinatura do orientador

FICHA CATALOGRÁFICA

Gonçalves, Cilene Maria Marques

Método para gestão do custo da construção no processo de projeto de edificações / C.M.M. Gonçalves. -- ed.rev. -- São Paulo, 2011.

$182 \mathrm{p}$.

Dissertação (Mestrado) - Escola Politécnica da Universidade de São Paulo. Departamento de Engenharia de Construção Civil.

1. Construção civil (Custos) 2. Orçamento parametrizado I. Universidade de São Paulo. Escola Politécnica. Departamento de Engenharia de Construção Civil II. t. 


\section{DEDICATÓRIA}

Dedico esta dissertação ao Elias Koshevnikoff, que um dia plantou a semente do "pensar" um orçamento de maneira não convencional.

Ao Luiz Henrique Ceotto, meu "parceiro profissional" e a pessoa mais admirável que conheço, que, com sua competência, conhecimento e dedicação, sempre me incentivou e orientou, fazendo a semente se transformar e frutificar.

E, finalmente, dedico este trabalho aos meus pais, Edson Gonçalves "in memoriam" e Izolina Marques Gonçalves, que sempre valorizaram a educação como nosso maior bem. 


\section{AGRADECIMENTOS}

Ao Professor Silvio Melhado, que disponibilizou conhecimento e muito tempo para me orientar de forma amiga e competente.

Ao colega Cláudio Ferreira Júnior, meu "Google particular", pela imensurável ajuda na busca de material bibliográfico.

Às amigas Cintia Vedovello e Ana Cristina Gualberto, pelo suporte, paciência e competência com que me apoiaram e incentivaram.

À amiga Regiane Pessarello, que, com sua análise crítica, fez evoluir meu trabalho com comentários esclarecedores e sugestões de bibliografia.

À empresa Tishman Speyer, pelo apoio e incentivo, permitindo minha ausência no horário de trabalho, possibilitando maior dedicação ao mestrado.

Aos meus familiares, que entenderam minha ausência nas comemorações importantes. 
Dê-me uma alavanca e um ponto de apoio e eu moverei o mundo. Arquimedes (matemático, físico e inventor grego) 


\section{RESUMO}

Devido à característica cíclica do mercado da construção civil, as margens de lucro das incorporadoras podem ser facilmente afetadas. Portanto, a assertividade do custo no momento da decisão da compra do terreno, e a sua variação entre o momento da decisão de se empreender e a conclusão do projeto deve ser pequena, de maneira a não comprometer o retorno esperado.

Notou-se uma fraqueza na área da engenharia quanto à definição do custo no momento do estudo da viabilidade do negócio e ao suporte de custo quanto às decisões tomadas durante o desenvolvimento do projeto. $O$ que se pratica pelo mercado é o preço parametrizado por $\mathrm{m}^{2}$ de área (construída, privativa ou equivalente), tendo como referência os custos atingidos por outros projetos.

Após a definição desse primeiro custo, o projeto só será avaliado quando já contar com a aprovação dos órgãos competentes e a venda para o cliente estiver iniciada. O custo final da construção pode ser difícil de ser atingido, pois todo o comprometimento já está consolidado baseado nas decisões tomadas durante seu desenvolvimento. Nesse momento, a construtora definirá seu primeiro custo, mas só terá um valor mais confiável após todos os projetos estarem, pelo menos, na fase de projeto básico. O custo a ser conhecido nessa fase pode surpreender negativamente se não forem tomados cuidados com sua análise.

O que se apresenta, nesta dissertação, é um método de parametrização simples e eficaz, que tem rapidez e agilidade para análises de engenharia de valor e decisões arquitetônicas, suportado pela parametrização de custos de construção descritos num Plano de Contas único desde o início do processo do negócio até a fase de construção, contribuindo para a rastreabilidade do processo, para facilitar as análises de cada fase e para a retroalimentação do processo de orçamentação.

Palavras-chave: parametrização de custos, orçamento parametrizado, engenharia de valor, construção de edifícios, projetos. 


\section{ABSTRACT}

The civil construction industry has cycling characteristic and low profitability; therefore, the markup can be easily affected. The Real Estate companies profit depend on the accuracy of the cost defined at the time of the decision to buy the site and still, that the cost variance between the moment of the decision to undertake the project and its conclusion be little, in order do not affect the expected return.

A weakness was observed in civil engineering field related to cost definition at the business feasibility phase and to the cost support in the decisions making during the design process. What is practice in the market is the cost based on the area (built, private or equivalent) having as a reference the final costs of previous projects. After this first cost, another evaluation will be done when the design was approved by the municipality and the sales have begun.

At this moment, the construction company gives the first cost, but it will be reliable only after all drawings are at least at the basic level. The cost at that phase could surprise in a negative manner if the cost analyzes were not carefully done.

What intends in this dissertation is to present a simple and effective parameterization method, with promptitude and agility to make engineering value analyzes and architectural decisions, supported by the construction cost parameterization described at the only work break down spread sheet, from the beginning of the business process to the end of construction phase, contributing for process traceability, to facilitate each phase analyze and for budgeting process feedback.

Key words: cost parameterization, parametrized budget, value engineering. 


\section{LISTA DE ILUSTRAÇÕES}

Figura 1 Representação esquemática das interações de uma equipe multidisciplinar genérica: Engenharia Simultânea - Fabrício (2002)

Figura 2 Capacidade de influenciar o Custo Final de um empreendimento de edifício ao longo de suas fases (CII, 1987) apud Melhado (1995)

Figura 3 Ajustes no processo de concepção

Figura $4 \quad \mathrm{O}$ avanço do empreendimento em relação à chance de reduzir o custo e falhas do edifício. Fonte: Hammarlund e Josephson (1992)

Figura 5 Processo de desenvolvimento do projeto e as etapas do empreendimento (MELHADO, 2005) x relação com os Manuais de Escopo de Projetos e Serviços para a Indústria Imobiliária

Figura $6 \quad$ Fluxo de etapas de projeto 62

Figura 7 Croqui esquemático: Edifício Residencial - 4 apartamentos

Figura 8 Croqui esquemático: Edifício Residencial - 2 apartamentos

Figura 9 Estrutura Organizacional - Design \& Construction

Figura10 Fluxo do Processo com etapas de validação

Figura 11 Explicativo da importância da relação AC/AP. Fonte: Empresa 124 estudada (Outubro, 2008)

Figura 12 Croqui dos terrenos a serem comprados (lotes verdes)

Figura 13 Croqui do terreno com os lotes comprados - Cenário 2

Figura 14 Croqui do terreno: implantação da torre - Cenário 2

Figura 15 Estudo de massa preliminar - Cenário 3

Figura 16 Programa do empreendimento - Cenário 3

Figura 17 Croqui do terreno: implantação da torre - Cenário 3 


\section{LISTA DE GRÁFICOS}

Gráfico 1 Custo $/ \mathrm{m}^{2}$ de área privativa $\mathrm{x}$ área privativa - Alto Padrão

Gráfico 2 Custo $/ \mathrm{m}^{2}$ de área privativa $x$ proporção AC/AP - Alto Padrão

Gráfico 3 Custo $/ \mathrm{m}^{2}$ de área equivalente $\mathrm{x}$ área equivalente - Alto

Gráfico 4 Padrão

Gráfico 5

Custo $/ \mathrm{m}^{2}$ de área construída $\mathrm{x}$ área construída - Alto Padrão

Custo $/ \mathrm{m}^{2}$ de área privativa $\mathrm{x}$ área privativa - Médio Padrão 3 dormitórios

Gráfico 6 Custo $/ \mathrm{m}^{2}$ de área privativa $\mathrm{x}$ proporção $\mathrm{AC} / \mathrm{AP}$ - Médio Padrão - 3 dormitórios

Gráfico 7 Custo $/ \mathrm{m}^{2}$ de área equivalente $\mathrm{x}$ área equivalente - Médio Padrão - 3 dormitórios

Gráfico 8 Custo $/ \mathrm{m}^{2}$ de área construída $\mathrm{x}$ área construída - Médio Padrão - 3 dormitórios

Gráfico 9 Custo $/ \mathrm{m}^{2}$ de área privativa $\mathrm{x}$ área privativa - Médio Padrão 4 dormitórios

Gráfico 10 Custo $/ \mathrm{m}^{2}$ de área privativa $\mathrm{x}$ proporção $\mathrm{AC} / \mathrm{AP}$ - Médio Padrão - 4 dormitórios

Gráfico 11 Custo $/ \mathrm{m}^{2}$ de área equivalente $\mathrm{x}$ área equivalente - Médio Padrão - 4 dormitórios

Gráfico 12 Custo $/ \mathrm{m}^{2}$ de área construída $\mathrm{x}$ área construída - Médio Padrão - 4 dormitórios

Gráfico 13 Custo $/ \mathrm{m}^{2}$ de área privativa x área privativa - Baixo Padrão

Gráfico 14 Custo $/ \mathrm{m}^{2}$ de área privativa $x$ proporção AC/AP - Baixo Padrão

Gráfico 15 Custo $/ \mathrm{m}^{2}$ de área equivalente $\mathrm{x}$ área equivalente - Baixo Padrão

Gráfico 16 Custo $/ \mathrm{m}^{2}$ de área construída $\mathrm{x}$ área construída - Baixo 133 Padrão

Gráfico 17 Parametrização das quantidades de estrutura (fundo pontilhado) 


\section{LISTA DE QUADROS}

Quadro 1 Informações sobre o produto residencial $\quad 77$

Quadro 2 Informações sobre o produto comercial 77

Quadro $3 \quad$ Dados Primários 83

Quadro $4 \quad$ Principais Características - Edifício Comercial Concluído 126

Quadro 5 Principais Características - Edifício Comercial em 132 Construção Aprovação

Quadro $7 \quad$ Dados Primários - Cenário $1 \quad 140$

Quadro $8 \quad$ Dados Primários - Cenário $2 \quad 141$

Quadro 9 Dados Primários - Cenário $3 \quad 145$ 


\section{LISTA DE TABELAS}

Tabela 1 Composição do preço de venda de um empreendimento imobiliário (informação verbal)

Tabela 2 Diferenças e características das avaliações, estimativas e orçamentos (ÁVILLA; LIBRELOTTO; LOPES, 2003)

Tabela 3 Custos finais de empreendimentos de quatro dormitórios Alto Padrão

Tabela 4 Custos finais de empreendimentos de três e quatro dormitórios - Médio Padrão

Tabela 5 Custos finais de empreendimentos de dois dormitórios Baixo Padrão

Tabela 6 Métodos de estimativa preliminar de custo (ASHWORTH, 2010)

Tabela 7 Coeficiente de irregularidade - Edifício Residencial: quatro apartamentos por andar

Tabela 8 Coeficiente de irregularidade - Edifício Residencial: dois apartamentos por andar

Tabela 9 Exemplo das dimensões dos ambientes para parametrização

Resumo dos histogramas

$\begin{array}{ll}\text { Tabela } 11 \text { Cronograma físico-financeiro } & 119\end{array}$

Tabela 12 Total de desembolso com e sem "colchão inflacionário" Taxa de Inflação: 7\%

Tabela 13 Custo dos diversos estudos de massa. Fonte: Empresa estudada

Tabela 14 Dados Primários - Estudo de Massa - Arquiteto

Tabela 15 Dados Secundários e Terciários - Parametrização com apoio de coeficientes históricos

Tabela 16 Comparativo das diversas fases de negócio

Tabela 17 Parametrização das quantidades de estrutura (fundo pontilhado)

Tabela 18 Evolução das análises de quantidades e custo da estrutura 
Tabela 19 Evolução das grandes contratações (empreitada global)

Tabela 20 Caso Residencial - Fase de Aprovação

Tabela 21 Caso Residencial - Fase de Viabilidade - Cenário 1

Tabela 22 Caso Residencial - Fase de Viabilidade - Cenário 2

Tabela 23 Caso Residencial - Fase de Viabilidade - Cenário 3 


\section{LISTA DE ABREVIATURAS E SIGLAS}

ABNT

AsBEA

BDI

CEPAC

COE

CUB

$D \& C$

EUA

INCC

InfoHab

NBR

NFPA

SindusConMG

TCPO

VGV
Associação Brasileira de Normas Técnicas

Associação Brasileira dos Escritórios de Arquitetura

Benefícios e Despesas Indiretas

Certificado de Potencial Adicional de Construção

Código de Edificações

Custo Unitário Básico

Design and Construction

Estados Unidos da América

Índice Nacional de Construção Civil

Centro de Referência e Informação em Habitação

Norma Brasileira

National Fire Protection Association

Sindicato da Indústria da Construção Civil do Estado de Minas Gerais

Tabelas de Composições de Preços para Orçamentos

Valor Geral de Vendas 


\section{SUMÁRIO}

1 INTRODUÇÃO 17

1.1 Origem do Trabalho 17

1.2 IMPORTÂNCIA DO TRABALHO 21

1.3 Objetivo do Trabalho 25

1.4 Estrutura do Trabalho 25

1.5 Metodologia da Pesquisa 26

2 FUNDAMENTOS CONCEITUAIS E REVISÃO 28 BIBLIOGRÁFICA

2.1 DEFINIÇÃO DE ORÇAMENTO 28

2.2 A ProblemÁtICA do Processo ORÇAMENTÁRIO 32

2.3 TÉCNICAS ORÇAMENTÁRIAS 52

2.4 EVOLUÇÃo do ORÇAMENTO E SUA CONFIABILIDADE FACE ÀS 58 INFORMAÇÕES NAS DIVERSAS FASES DO EMPREENDIMENTO

3 MÉTODO DE ORÇAMENTAÇÃO POR 67 PARAMETRIZAÇÃO

3.1 Conceito de Parametrização $\quad 67$

3.2 Plano de Contas 71

3.3 O PROCESSO dE PARAMETRIZAÇÃo: OBTENÇÃo dOS DAdOS E 75 PRIORIDADES

3.4 O Processo de Parametrização: Obtenção de Algoritmos

3.4.1 Parametrização de Quantidades para os Custos Diretos

3.4.2 Parametrização das Despesas Indiretas

3.4.3 Parametrização de Custos

3.4.3.1 Parametrização de Custos Diretos - Empreitada Global

3.4.3.2 Parametrização de Custos Unitários (Diretos e Indiretos) 
4.1 ApRESENTAÇÃO DA EMPRESA 114

4.2 Fluxo do Processo de Projeto 115

4.3 Consideração do FluXo de Desembolso no Processo 117 ORÇAMENTÁRIO

4.4 ESTUdOS DE CASO

4.4.1 Estudo de Caso 1 - Edifício Comercial Concluído 125

4.4.2 Estudo de Caso 2 - Edifício Comercial em Fase Inicial de 132 Construção

4.4.2.1 Evolução das quantidades de estrutura

4.4.2.2 Evolução das contratações das instalações prediais, ar condicionado e elevadores

4.4.3 Estudo de Caso 3 - Edifício Residencial em Fase de Aprovação

4.4.4 Estudo de Caso 4 - Empreendimento em Fase de Viabilidade

5 CONSIDERAÇÕES FINAIS 